\title{
Conjugated Oligoelectrolyte Electron Transport/Injection Layers for Organic Optoelectronic Devices
}

\author{
Renqiang Yang, ${ }^{\dagger}$ Yunhua $\mathrm{Xu},{ }^{\dagger,}$ Xuan-Dung Dang, ${ }^{\dagger}$ Thuc-Quyen Nguyen, ${ }^{\dagger}$ Yong Cao, ${ }^{*}$ \\ and Guillermo C. Bazan*,† \\ Mitsubishi Chemical Center for Advanced Materials, Department of Chemistry \& \\ Biochemistry, Department of Materials, Institute for Polymers and Organic Solids, \\ University of California, Santa Barbara, California 93106, Institute of Polymer \\ Optoelectronic Materials and Devices, South China University of Technology, \\ Guangzhou 510640, China \\ Corresponding Author: bazan@chem.ucsb.edu
}

\section{$<$ Supporting Information $>$}

\section{Fabrication of PLEDs}

Devices were fabricated on pre-patterned indium-tin oxide (ITO) with a sheet resistance 10-20 $\Omega /$. The substrate was cleaned under ultrasonic conditions with detergent, de-ionized water, acetone and isopropanol. An UV plasma treatment was made for 40 minutes as the final step of substrate cleaning procedure. On top of the ITO, a layer of polyethylenedioxythiophene:polystyrene sulfonic acid (PEDOT:PSS) film with thickness of $60 \mathrm{~nm}$ was spin-coated from its aqueous dispersion (Baytron P 4083, Bayer AG). The PEDOT:PSS film was dried at $180^{\circ} \mathrm{C}$ for 10 minutes inside a glove box filled with nitrogen. A solution of poly[2-methoxy-5-(2'-ethylhexyloxy)-1,4phenylenevinylene] (MEH-PPV, $4 \mathrm{mg} / \mathrm{mL}$ ) in toluene, was spin-coated on top of the ITO/PEDOT:PSS surface. The typical thickness of the MEH-PPV layer was approximately $80 \mathrm{~nm}$. Subsequently, a layer of FFF-BIm 4 was spin-coated from its methanol solution $(1 \mathrm{mg} / \mathrm{mL})$. Finally, a $100 \mathrm{~nm}$ thick aluminum capping layer was thermally deposited by vacuum evaporation through a mask at a base pressure below $1 \times$ $10^{-6}$ torr. The spin coating of EL layers and the device performance tests were carried out within a glove box with nitrogen circulation. The control devices were fabricated and 
tested with the following configuration, ITO/PEDOT/MEH-PPV/Ba/Al and ITO/PEDOT/MEH-PPV/Al, respectively. Current density-voltage-luminance ( $J-V-L)$ characteristics were measured with a computerized Keithley 2602 Source Measure Unit combined with a photo diode.

\section{Luminous Efficiency vs. Current Density Characteristics}

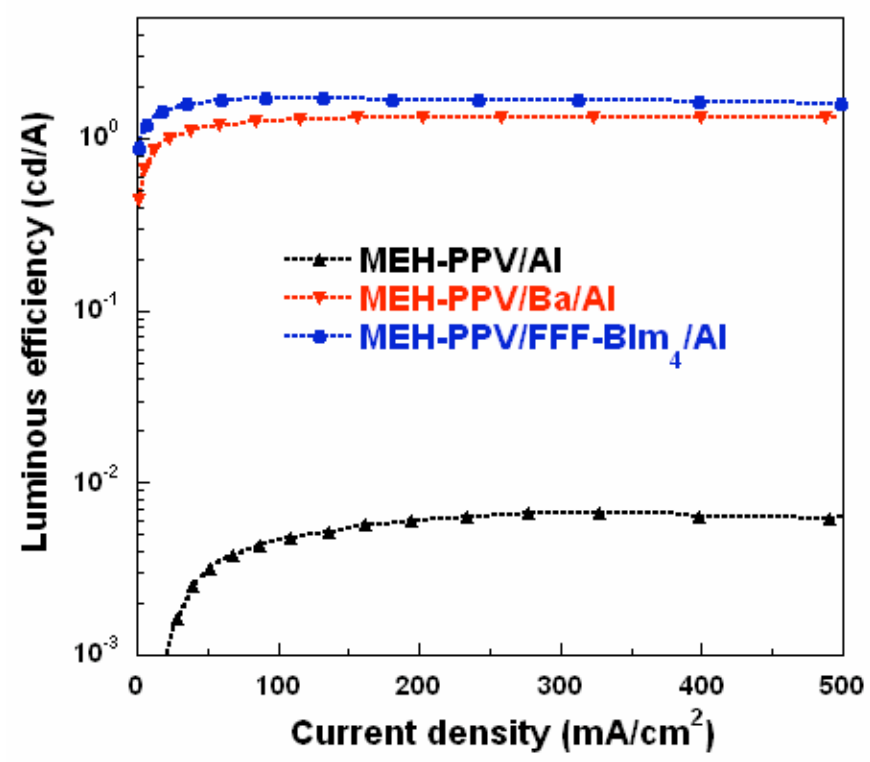

Figure S1. The luminous efficiency vs. current density of the PLEDs. 
Table 1. Summary of PLED performance.

\begin{tabular}{|c|c|c|c|c|c|c|}
\hline \multirow{2}{*}{ Device structure } & \multirow{2}{*}{$\begin{array}{l}V_{\text {th }} \\
(\mathrm{V})\end{array}$} & \multicolumn{4}{|c|}{ Max Efficiency } & \multirow{2}{*}{$\begin{array}{c}\text { Max } \\
\text { Lumin. } \\
\left(\mathrm{cd} / \mathrm{m}^{2}\right)\end{array}$} \\
\hline & & $\mathrm{cd} / \mathrm{A}$ & $\mathrm{cd} / \mathrm{m}^{2}$ & V & $\begin{array}{l}\mathrm{mA} / \\
\mathrm{cm}^{2}\end{array}$ & \\
\hline $\begin{array}{l}\text { ITO/PEDOT/MEH- } \\
\text { PPV/Al }\end{array}$ & 3.0 & 0.007 & 46 & 6.0 & 652 & 96 \\
\hline $\begin{array}{l}\text { ITO/PEDOT/MEH- } \\
\mathrm{PPV} / \mathrm{Ba} / \mathrm{Al}\end{array}$ & 2.0 & 1.33 & 3442 & 4.2 & 259 & 18552 \\
\hline $\begin{array}{l}\text { ITO/PEDOT/MEH- } \\
\text { PPV/FFF-BIm } 4 / \mathrm{Al}\end{array}$ & 1.9 & 1.69 & 2240 & 3.4 & 132 & 20801 \\
\hline
\end{tabular}

\section{Dimensions of the shadow mask:}
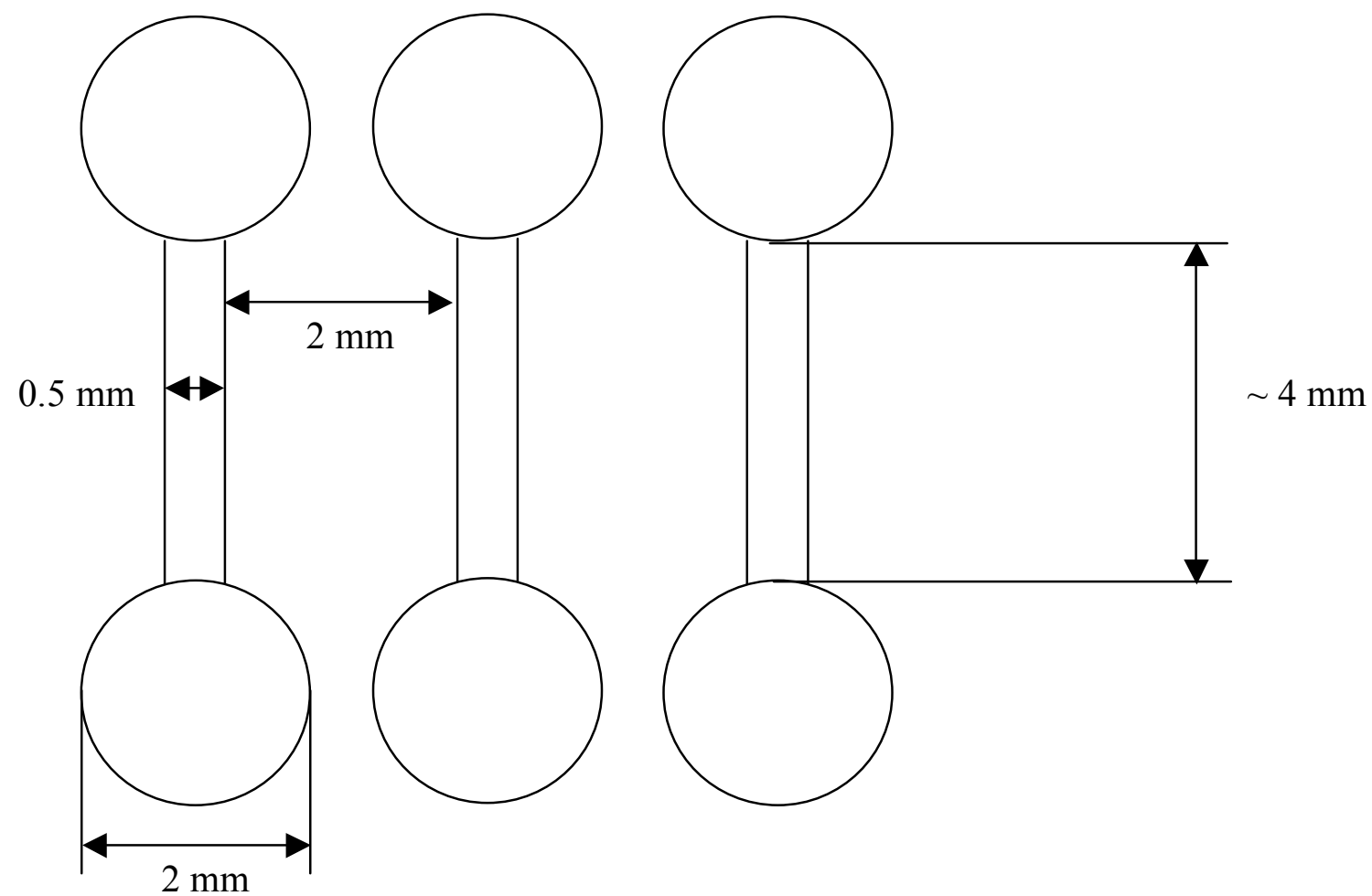


\section{XPS Analysis}
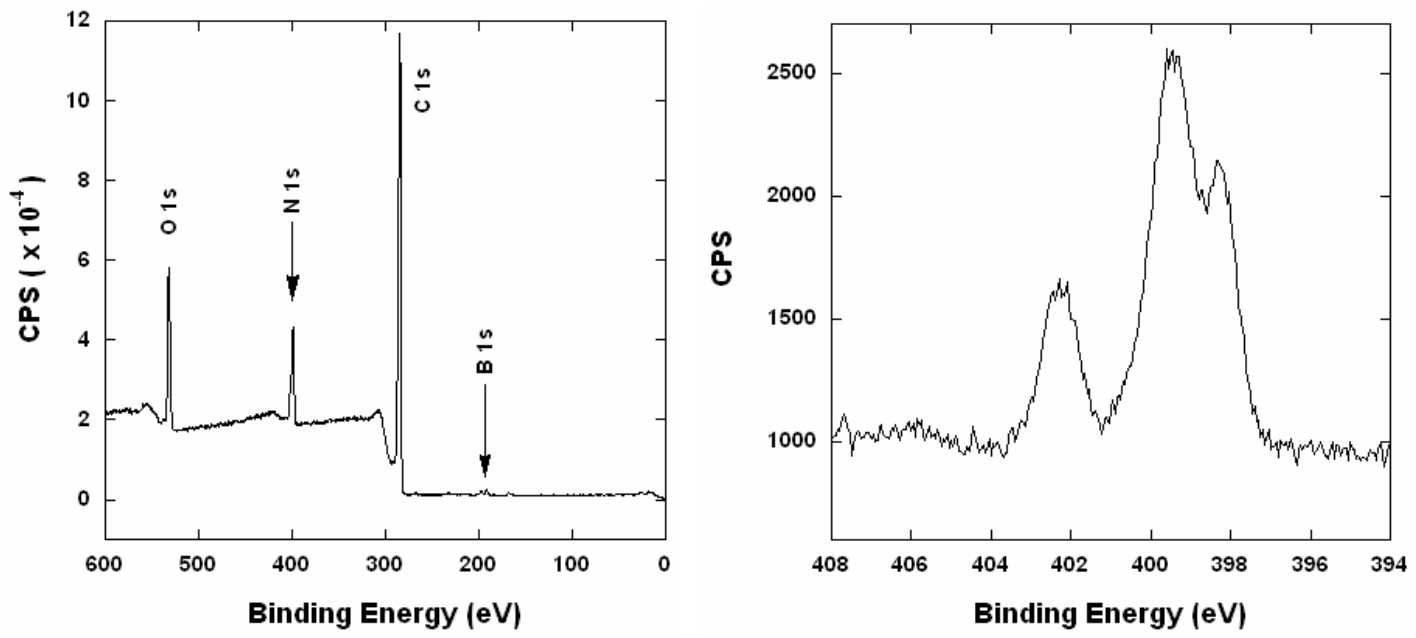

Figure S-2. XPS spectra from the film between two Al electrodes, the device structure is ITO/PEDOT:PSS/MEH-PPV/FFF-BIm 4 /Al. Left: full spectra, right: high resolution spectra due to N1s peaks. The spectra show that the surface between Al electrodes contains FFF-BIm 4 .
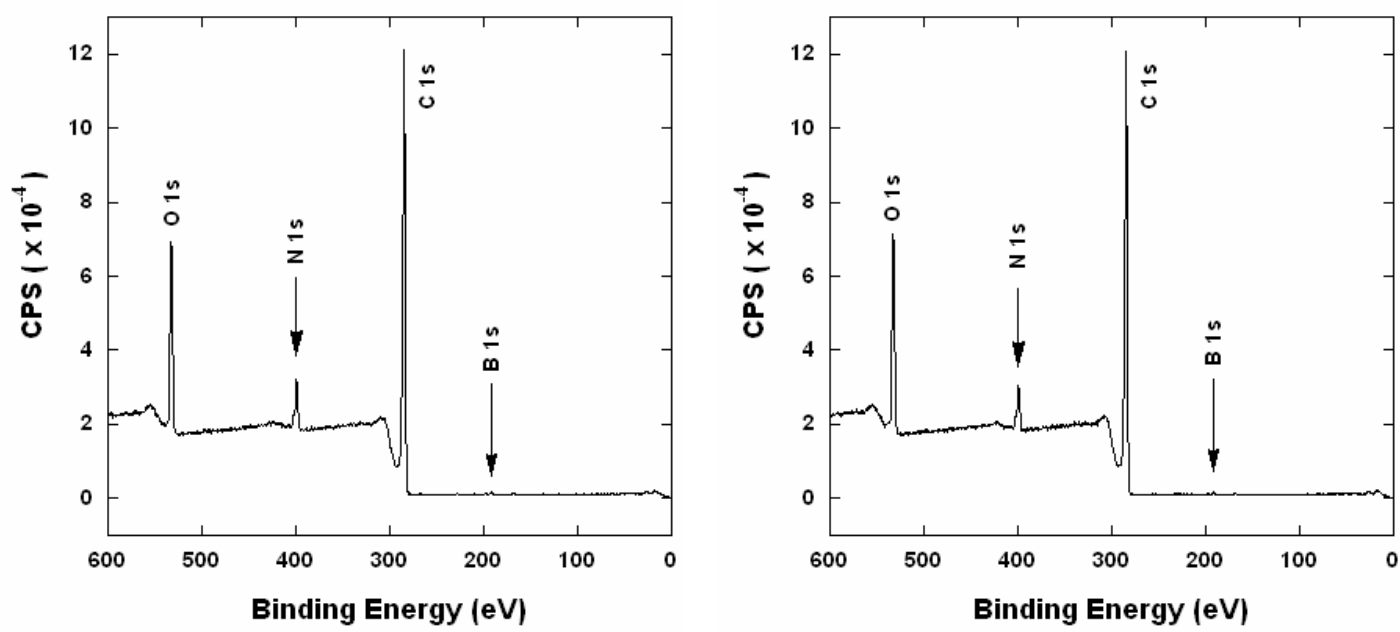

Figure $\boldsymbol{S}$-3. XPS spectra of two positions on the ITO/PEDOT:PSS/MEH-PPV/FFF$\mathbf{B I m}_{4}$ surface prior to Al deposition. The spectra are similar to Figure S-2. 


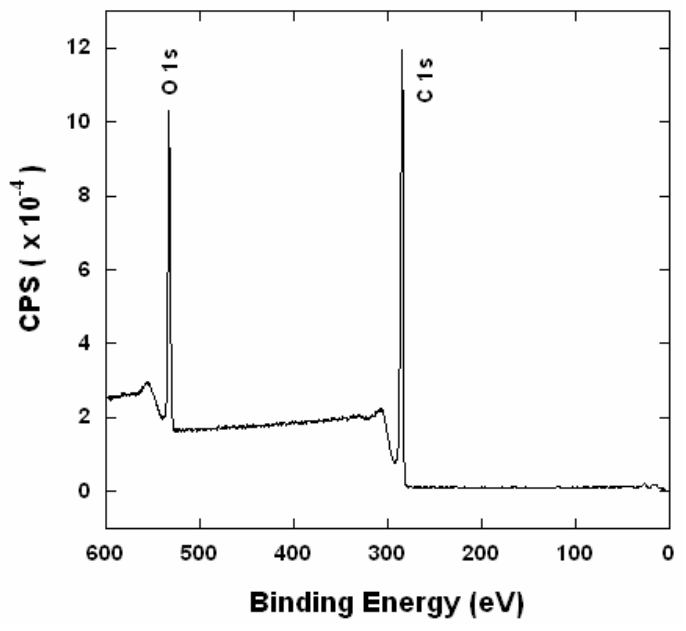

Figure S-4. XPS spectra from the film between two electrodes in a device of configuration ITO/PEDOT:PSS/MEH-PPV/Ba/Al. The spectra show that the surface between $\mathrm{Al}$ electrodes is exclusively MEH-PPV. Note the absence of N1s peaks. 
Photographic capture of PLED emission (Size: $100 \mu \mathrm{m}$ ),

Shown below are images that were obtained by using a microscope objective and a digital camera attached to a probe station (Signaton) that was housed in a nitrogen glove box. The images are $100 \mu \mathrm{m}$ on each side.

Device structure: ITO/PEDOT/MEH-PPV/FFF-BIm $4 / \mathrm{Al}$
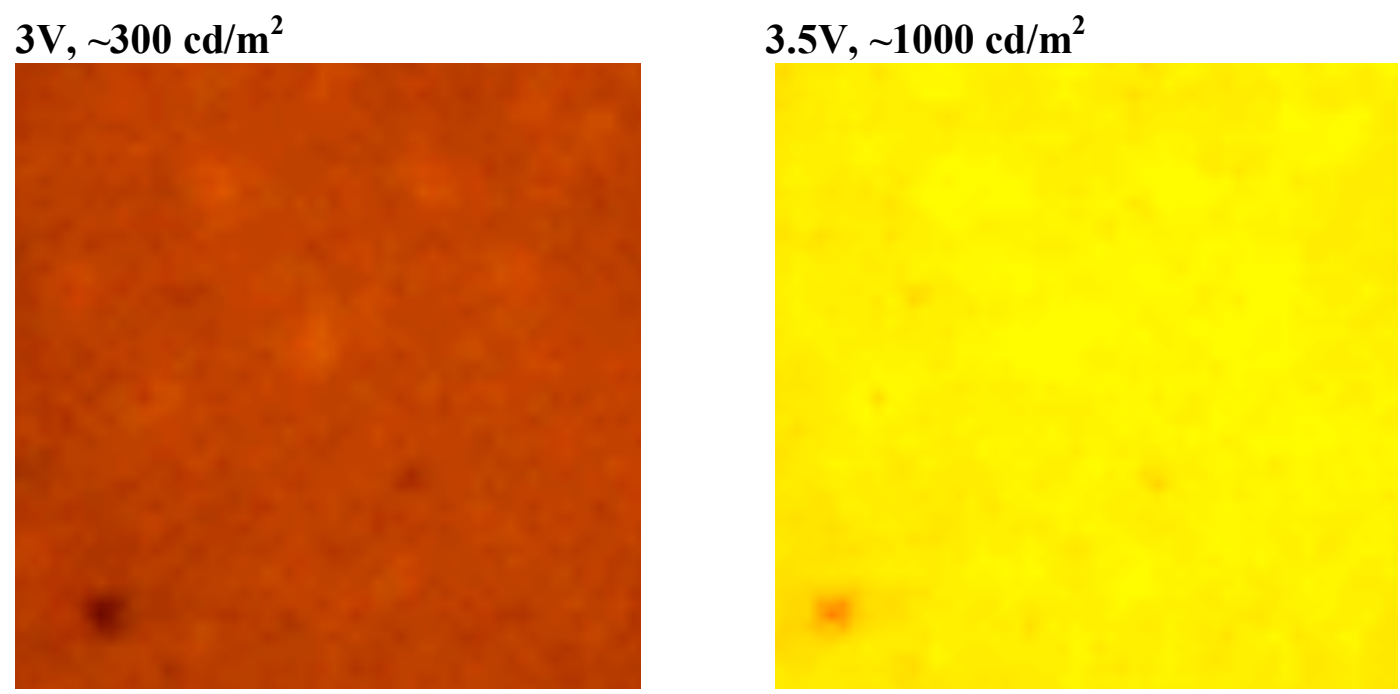

$4 \mathrm{~V}, \sim 2500 \mathrm{~cd} / \mathrm{m}^{2}$

$5 \mathrm{~V}, \sim 7000 \mathrm{~cd} / \mathrm{m}^{2}$

$\overline{20 \mu \mathrm{m}}$ 


\section{Effect of the conjugated oligoelectrolyte layer on durability of devices.}

The effect of introducing the conjugated oligoelectrolyte layer on device durability was tested at a constant current and initial luminance of $200 \mathrm{~cd} / \mathrm{m}^{2}$ inside nitrogen glove box. The results show, within the first 1000 minutes, that MEH-PPV/FFF$\mathbf{B I m}_{4} / \mathrm{Al}$ devices have similar durability when compared with control devices with the $\mathrm{MEH}-\mathrm{PPV} / \mathrm{Ba} / \mathrm{Al}$ structure.

Device structure: ITO/PEDOT/MEH-PPV/FFF-BIm $4 / \mathrm{Al}$

Control device: ITO/PEDOT/MEH-PPV/Ba/Al

Current density: $0.765 \mathrm{~mA} / \mathrm{cm}^{2}$ for FFF-BIm 4 devices

$0.85 \mathrm{~mA} / \mathrm{cm}^{2}$ for control devices

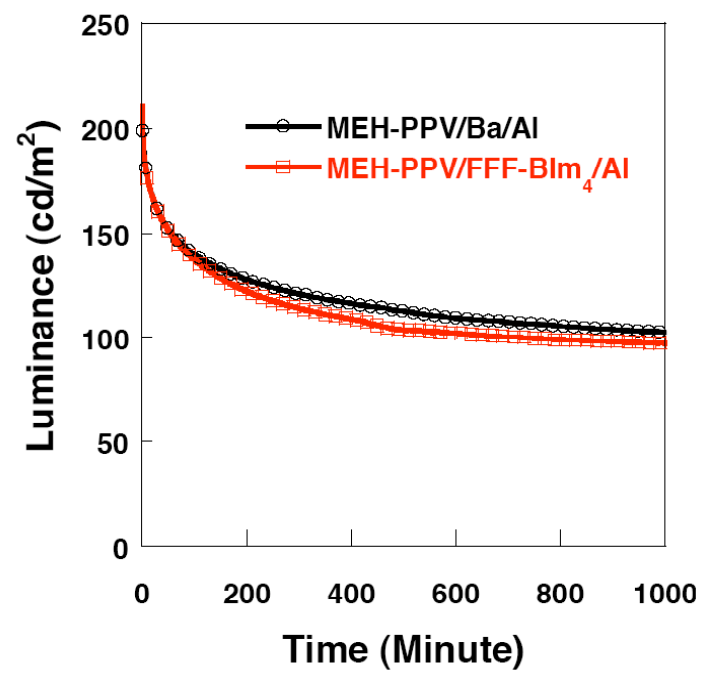

Figure $\boldsymbol{S}$-5. Luminance vs. time characteristics of ITO/PEDOT/MEH-PPV/FFF$\mathbf{B I m}_{4} / \mathrm{Al}$ (red) and ITO/PEDOT/MEH-PPV/Ba/Al devices with an initial luminance of $200 \mathrm{~cd} / \mathrm{m}^{2}$. 


\section{Synthetic Details}

All commercial chemical reagents were obtained from Aldrich and used as received. The ${ }^{1} \mathrm{H}$ and ${ }^{13} \mathrm{C}$ NMR spectra were collected on a Varian ASM-100 $400 \mathrm{MHz}$ spectrometer.

9,9;9',9';9",9"'-Hexakis(6"'-bromohexyl)-2,2';7',2"'-trifluorene. A mixture of 2,7-bis(4,4,5,5-tetramethyl-1,3,2-dioxaborolan-2-yl)-9,9-bis(6'-bromohexyl)fluorene (0.5 mmol, $372 \mathrm{mg})$, 2-bromo-9,9-bis(6'-bromohexyl)fluorene $\mathrm{i}^{\mathrm{i}}(1.075 \mathrm{mmol}, 614 \mathrm{mg}$ ) and $\mathrm{Pd}\left(\mathrm{PPh}_{3}\right)_{4}(15 \mathrm{mg})$ were dissolved in $8 \mathrm{~mL}$ toluene and $2.5 \mathrm{~mL} 2 \mathrm{M} \mathrm{Na}_{2} \mathrm{CO}_{3}$ aqueous solution (Scheme 1). The resulting mixture was refluxed while stirring for two days, and was then cooled to room temperature and diluted with $150 \mathrm{~mL}$ of dichloromethane. The organic layer was collected, washed with brine and water, and was then dried over sodium sulfate. After evaporation the solvent, the residue was purified by chromatograph on silica gel using hexanes : $\mathrm{CH}_{2} \mathrm{Cl}_{2}=2: 1$, to give a white solid: $508 \mathrm{mg}(69 \%) .{ }^{1} \mathrm{H} \mathrm{NMR}$ (400 MHz, $\left.\mathrm{CDCl}_{3}\right) . \delta(\mathrm{ppm}): 7.83(\mathrm{q}, 4 \mathrm{H}), 7.76(\mathrm{br}, 2 \mathrm{H}), 7.70(\mathrm{~m}, 4 \mathrm{H}), 7.65$ (d, 4H), 7.37 (m. 6H), 3.29 (t, 12H, J=6.8 Hz), 2.10 (br, 12H), 1.69 (m, 12H), 1.24 (m, 12H), 1.13 (m, 12H), 0.75 (br, 12H). ${ }^{13} \mathrm{C}$ NMR (100 MHz, $\left.\mathrm{CDCl}_{3}\right), \delta(\mathrm{ppm}): 151.63,151.36,150.78$, $140.96,140.64,140.60,140.24,127.38,127.19$, 126.52, 126.41, 123.05, 121.48, 121.39, $120.31,120.25,120.05,55.47,55.29,40.46,34.25,32.81,29.25,27.96,23.86,23.78$. FAB/Mass, 1472. Anal. Calcd for $\mathrm{C}_{75} \mathrm{H}_{92} \mathrm{Br}_{6}$ : C, 61.16; H, 6.30. Found: C, 61.02; H, 6.25 .

\section{9,9;9',9';9",9"'-Hexakis(6"''-N,N,N-trimethylammonium)hexyl)-2,2';7',2'"-}

trifluorene hexabromide (FFF-Br). Condensed trimethylamine $(2.5 \mathrm{ml})$ was added dropwise to a solution of 9,9;9',9';9",9"-hexakis(6"'-bromohexyl)-2,2';7',2"-trifluorene $(147 \mathrm{mg}, 0.1 \mathrm{mmol})$ in tetrahydrofurnan $(20 \mathrm{~mL})$ at $-78^{\circ} \mathrm{C}$. The mixture was allowed to warm up to room temperature gradually. After stirring $24 \mathrm{~h}$, some precipitate was redissolved by addition of excess methanol. An extra $2 \mathrm{~mL}$ of trimethylamine were added at $-78{ }^{\circ} \mathrm{C}$, and the mixture was stirred vigorously for $24 \mathrm{~h}$. After removal of the solvents, hexanes and acetone were added to wash the residue. Drying in vacuum oven gave the target oligomer (144 mg, 79\%) as white solid. ${ }^{1} \mathrm{H}$ NMR (400 $\left.\mathrm{MHz}, \mathrm{CD}_{3} \mathrm{OD}\right) . \delta$ (ppm): 7.88 (q, 4H), 7.75 (m, 10H), 7.44 (m, 2H), 7.34 (br, 4H), 3.22 (m, 12H), 3.03 (s, 54H), 2.18 (br, 12H), 1.58 (br, 12H), 1.16 (br, 24H), 0.68 (br, 12H). ${ }^{13} \mathrm{C}$ NMR (100 MHz, 
$\left.\mathrm{CD}_{3} \mathrm{OD}\right), \delta(\mathrm{ppm}): 153.00,152.63,152.02,142.43,142.19,141.81,141.73,128.57$, $128.39,127.56,127.46,124.24,122.29,121.57,121.46,121.06,67.74,56.84,56.56$, 53.66, 41.47, 41.34, 30.59, 30.44, 27.14, 27.03, 25.21, 24.97, 23.93, 23.81. ESI/TOF, 224 $(\mathrm{M}-6 \mathrm{Br})^{6+}, 285(\mathrm{M}-5 \mathrm{Br})^{5+}, 376(\mathrm{M}-4 \mathrm{Br})^{4+}, 529(\mathrm{M}-3 \mathrm{Br})^{3+}, 833(\mathrm{M}-2 \mathrm{Br})^{2+}$. Anal. Calcd for $\mathrm{C}_{93} \mathrm{H}_{146} \mathrm{Br}_{6} \mathrm{~N}_{6}$ : C, 61.12; H, 8.05; N, 4.60. Found: C, 60.03; H, 7.89; N, 4.43. XPS spectra, Figure S3.

General procedure for counterion exchange. 9,9;9',9';9",9"-Hexakis(6"'-N,N,Ntrimethylammonium)hexyl)-2,2';7',2"-trifluorene bromide (91 $\mathrm{mg}, 0.05 \mathrm{mmol}$ ) was dissolved in $5 \mathrm{~mL}$ methanol. Subsequently, a solution with an excess of a salt bearing the anion of interest in $8 \mathrm{~mL}$ water was added. After stirring for half an hour, the mixture was poured into a 500 molecular weight cutoff (MWCO) symmetric cellulose ester membrane (Spectrum Laboratories, Inc.) sealed with closures, and immersed into a $2 \mathrm{~L}$ beaker filled with de-ionized water. The water inside the membrane was evaporated under reduced pressure after dialysis for three days. The product is obtained by drying under vacuum.

\section{9,9;9',9';9",9"'-Hexakis(6"'-N,N,N-trimethylammonium)hexyl)-2,2';7',2"-} trifluorene tetrakis(1-imidazolyl)borate (FFF-BIm $\left.{ }_{4}\right)$. FFF-Br $91.3 \mathrm{mg}(0.05 \mathrm{mmol})$ and sodium tetrakis(1-imidazolyl)borate $272 \mathrm{mg}(0.90 \mathrm{mmol})$ were used. The target FFFBIm $_{4}$ was obtained in $55 \%$ yield $\left(83 \mathrm{mg}\right.$ ). ${ }^{1} \mathrm{H}$ NMR (400 MHz, CD $\left.{ }_{3} \mathrm{OD}\right) . \delta(\mathrm{ppm}): 7.89$ (q, 4H), $7.74(\mathrm{~m}, 10 \mathrm{H}), 7.46(\mathrm{~m}, 2 \mathrm{H}), 7.34(\mathrm{br}, 4 \mathrm{H}), 7.11(\mathrm{~s}, 24 \mathrm{H}), 6.96(\mathrm{~s}, 24 \mathrm{H}), 6.76(\mathrm{~s}$, 24H), $3.20(\mathrm{~m}, 12 \mathrm{H}), 3.02$ (s, 54H), 2.17 (br, 12H), 1.56 (br, 12H), 1.14 (br, 24H), 0.68 (br, 12H). ESI/TOF, $224(\mathrm{M}-6 \mathrm{BIm} 4)^{6+}, 380\left(\mathrm{M}-4 \mathrm{BIm}_{4}\right)^{4+}$. Anal. Calcd for $\mathrm{C}_{165} \mathrm{H}_{218} \mathrm{~B}_{6} \mathrm{~N}_{54}$ : C, 65.56; H, 7.27; N, 25.02. Found: C, 59.97; H, 7.03; N, 23.87.

\section{References}

${ }^{\mathrm{i}}$ Wang, S.; Bazan, G. C. Adv. Mater. 2003, 15, 1425 